gresees to such a stage that the heart becomes incompetent and the cardio-vascular changes are sufficient to produce this water.logged condition, the patient can not long exist. It is true that therapeutic tests may be of value, but the therapeutic test is like the dead-house test. A man with kidney disease with changes in the heart and blood vessels, who is in a water-legged condition, does not have perfectly normal urine, as can be proven. If a nephritis occurs and continues long enough to have cardiac changes, incompetent heart, bronchitis, general anasarca, etc., he may have hemorrhages in the brain and elsewhere. There has been a condition mentioned in which arterio sclerosis, hypertrophy of the heart and scler osis of the blood vessels, and other evidences of Bright's disease occurred and yet no Bright's disease. I have tried to write my findings of the case, and also stated in my conclusions that in kidney disease the arterial sclerosis was marked and the pulse full and sustained. I am gratified that the paper has received the amount of discussion it has.

\section{DIABETIC GANGRENE.}

I'resented to the Section on the Practice of Medicine at the Forty.ninth Annual Meeting of the American Medical Association, held

$$
\text { at Denver, Colo.. June 7-10, } 1898 .
$$

BY N. S. DAVIS, JR., A.M., M.D.

PROFESSOR OF PRINCIPLES ANI PRACTICE OF MEDICINE AND OF CLINICAL MEDICINE, NORTHWESTERN UNIYERSTTY MEDICAL SCHOOL, ETC.

The following cases of gangrene associated with diabetes which have been observed by me during the last fow years, inspired me to look through the rather meager literature of the subject with care.

J. G., 62 years old, was a ruddy and hearty Englishman, who was habitually careless and negligent of himself and his health. In July, 1892, I found that he was a diabetic. As he promptly improved, gaining in strength and flesh, he did not persevere with the prescribed treatment. He was not seen a second time until September. The last joint of the middle finger of his left hand was then purplish red, swollen and painful. The skin on the ball of the finger was hard, slightly wrinkled and almost black. Pain was constant but not intense. The rest of the finger looked normal except at the first joint a red line of demarcation was discernable. This finger had not been scratched or injured. The gangrene was evidently spontaneous. His urine contained 1.3 per cent of sugar and had a sp. gr. of 1032. A week later he voided 2 quarts of urine, a quart less than before. It contained only a trace of sugar. Sensibility was entirely wanting in the last phalanx of the affected finger except at the sharply defined line of demarcation. The last phalanx was blue-black and perfectly mummified. Pain gradually disappeared. By the 24th of September the quantity of urine voided was normal, having a specific gravity of 1028 and containing no sugar. Sugar did not reappear until the end of October, when it occurred in 1.3 per cent. The urine had a specific gravity of 1031 . For several days prior to this examination he used farinaceous food freely. When he again adhered to a moderately rigid diabetic diet, sugar disappeared from his urine. The last phalanx gradually underwent spontaneous amputation and separated completely from the healthy tissue the first of November. The stump healed nicely. I saw him occasionally during the next three months. He gained in flesh, strength and vigor. There was no returs of glycosuria, although in January he suffered from a mild eczema of prepuce and scrotum. This man bad tortuous temporal arteries and nodulation of the left radial. A sphygmographic tracing showed the low round-topped waves produced by atheromatous arteries. When his finger was first found to be gangrenous amputation was advised, but he refused to submit to it, and when he learned later that spontaneous amputation might take place, was still more unwilling to have the knife used.

B. J. B., 62 years old, a lawyer of prominence in one of the smaller cities of Michigan, consulted me in November, 1894. He first learned that he had glycosuria in 1892 , when he was examined for life insurance. He was a large eater, moderate drinker, and eminently sedentary in habits. Ten years before he weighed 200 pounds; when he was first seen by me he weighed 177 . For two years he had not varied more than two or three pounds from this weight. He felt in good health, except that for some monthe there had been an ulcer on a callous spot on the ball of his right great toe. An offensive slough of small dimensions had separated from it. When I saw it healing had begun. There was a shallow ulcer in the center of a yellowish callous. Almost no pus came from it. It caused no pain and was only tender when the raw flesh was touched. The toe appeared healthy: A sample of his urine had a specific gravity of 1040 and contained 2.5 per cent. of sugar. His arteries were hard but not nodulated. His heart was not hypertrophic.

I did not see this patient again until September, 1895. The ulcer under his toe never healed entirely. Several times it seemed almost well but became worse again. Alongside of the callus on which the ulcer was located was a superficial blister filled with bloody serum. He had recently had a similar blister on the sole of the foot. Both had come without recognizable cause. His urine contained a trifle less sugar. His general health was good; he weighed 180 pounds.

The next visit I received from him was in June, 1896. The ulcer remained unhealed. It was sometimes scabbed over and at others was covered by a small amount of pus. Its diameter varied from one-third to one-half of an inch. A sample of his urine contained 3 per cent. of sugar. In Oetober of the same year, this patient was seen again. He thought his too was well until about the first of September, when he was much worried by business cares and lost flesh, the ulcer opened again, and in a symmetrical place upon the left big toe a large blister formed. When the latter was opened and the dead overlying skin removed, a considerable excavation with raised edges and suppurating surface was disclosed. I did not see him again for a year, until last October. Both ulcers were about the same. The whole of the left big toe was purplieh and slightly swollen. It was moderately tender and painful. In other ways he felt well. A sample of his urine had a specific gravity of 1033 and contained 2 per cent. of sugar.

This patient was seen by me at such long intervals that he can not be said to have had systematic treatment. Moreover, he was not abstemious as regards food, drink or tobacco. He kept the affected toes as clean as possible, and applied successively a great variety of antiseptic salves and powders. He had persistent glycosuria, but of very moderate grade of severity. He rarely made more urine than was normal, and the diabetic state caused no appreciable loss of flesh or ability for mental work. This case is interesting because of the character and chronicity of the ulcers, and finally, because of the symmettrical distribution of the ulcers upon both feet. When last seen by me, I feared the whole of the left great toe was about to become gangrenous.

Katherine E., 58 years old, born in Ireland, was first seen by me in July, 1895. For five months her right foot pained her. I found the toes and, to a less extent, the distal third of her foot reddened and painful. The pain ceased almost completely whenever she remained or the bed or lounge. There had been slight suppuration about one toe nail, and a superficial ulcer on one toe joint. Both these lesions had disappeared before I examined her foot. She had lost flesh during several months. She had never been stout, but was decidedly thin when she came to me. Her appetite was poor. She experienced no thirst. Her bowels were constipated. As far as she had observed her urine was normal. A week later the foot was less swollen and painful, but the toe next to the little one was numb, purplish red and looked as if about to become gangrenous. A sample of her urine had a specific gravity of 1028 , and contained 1.5 per cent. of sugar. Before the end of A ugust the last two phalanges of this toe were mummified. A line of demarcation developed at the second joint. On the toe next to the big one a moist slough formed over a space a quarter of an inch in diameter. She was making from three to four pints of urine daily. The glycosuria rapidly dimin ished and by the first of September ceased. Her foot remained about the same, causing varying degrees of pain. Slowly the mummified toe separated from the healthy tissue. The middle of December it was attached only by a few shreds of tissue, which separated with a little traction. The ulcer on the other toe was slowly improving. The stump of the amputated toe soon healed perfectly. A trace of sugar was discoverable in her urine at this time. In January the ulcer on the second too grew worse, although there was no glycosuria. By the first of February it had opened into the joint. Toward the end of the month I picked from the opening a small piece of dead bone. After this the wound slowly healed. In March, the following month, a gangrenous slough formed on the ball of the great toe of the same foot. The whole foot from the instep to the toes was a dull purplish red. The toes were slightly gwollen. The capillary circulation was extremely slow in the skin of the foot. Pain was not constant or considerable. Her urine contained a trace of sugar. During the summer she was comfortable, able to work and rarely troubled with pain in her 
foot. In October her left foot (not the one first affected) became painful. The second toe was purplish red. From one edge of the nail it bled slightly. A red streak stretched up to the instep from the base of this toe. Her urine contained about 1 per cent. of sugar. The foot became diffusely red and more painful, the second toe lost sensibility, one edge sloughed away, the remainder slowly mummified. A month later this toe began to separate from the sound flesh and the one next to it also became gangrenous and dried up. The foot improved and was only occasionally painful. She kept her leg in a horizontal position almost continuously. Two months later both toes came away, having undergone spontaneous amputation, one at the first joint the other at the second. This woman also refused amputation by the knife.

In this case the disappearance of sugar from the urine, while the mummified toes were separating from the healthy tissue and its reappearance just before and when gangrene began afresh, was noticeable. The superficial arteries of this patient were tortuous and hard, but not noticeably atheromatous. Nor were there changes in the heart which would suggest the possibility of extensive atheroma. Undoubtedly, however, atheroma existed in all three of these cases and was the prime cause of gangrene.

The first and third cases typify well the milder forms of spontaneous gangrene in diabetics. The successive invasion of different toes in the last case is noteworthy. The diminution and even disappearance of glycosuria in both cases, while mummification existed and spontaneous amputation of the phalanges was progressing. is interesting. A similar marked diminution or disappearance of glycosuria I have observed in several cases when tubercular disease of the lungs was active. 'Both cases were upon diabetic treatment, which consisted mainly in a regulation of diet, the use of arsenical preparations and at times opiates.

The second case at first was one of mal perforant, which is an occasional complication of diabetes. Kirmission (Arch. gén. de Méd., 1885) has reported seven cases of it associated with diabetes; Duvernoy (Arch. géu, de Méd., Paris, 1891, 603), four; Grascuel (Thesis, Paris, 1886), fourteen; and Williamson. four ("Diabetes Mellitus," R. T. Williamson, published by Y. J. Pentland, London, 1898). Gascuel found in ninetyone cases of mal perforent that it was associated fourteen times with diabetes. The association is evidently no more an accidental one than the association of diabetes and gangrene proper. That there is a more frequent association of gangrene and diabetes than chance would cause, was first pointed out by Marchel in 1852. Diabetic gangrene occurs much oftener in the legs and feet than elsewhere. Marchel makes note of thirty-five cases with the lesion below the knees, seven in the lungs and three in the hands, out of a total of 133 . In the remaining cases the lesions were very widely scattered. Hunt records three out of five cases of gangrene of the foet. In the cases which I find reported still more recently there is about the same proportional distribution of the lesion.

Sturgis (Bos. Med. and Surg. Jour., 1891, 261, cxxiv) has described an interesting case of gangrene of the lip in a diabetic of 64 . Sloughing occurred, but the wound finally healed. For three years the secretion of saliva had almost ceased in this patient's mouth, a condition which caused him great distress. During the period of inflammatory reaction after gangrene had occurred on his lip, saliva formed once more in his mouth. In this case Sturgis calls atten. tion to the great diminution of sugar in the urine after sloughing had occurred. Those cases of gangrene occurring in the course of diabetes which are associated with or superimposed upon inflammation, are undoubtedly chiefly due to the low vitality of tissues in diabetics, and the consequent euse with which putrefaction takes place in them. The frequency of gangrene of the lungs in diabetics, who also have tubercular or other disease of the lungs, can be accounted for in this way. The cause of spontaneous gangrene, which is not preceded by visible wounds or infection, is of more interest. Neuritis and atheroma have both been assigned as causes of the spontaneous gangrene of diabetes. Both lesions frequently accom. pany diabetes. Godlee (Med. Chi. and Trans., lxxvi, 37) admits two varieties of spontaneous diabetic gangrene, the one due to neuritis, the other to atheroma. He recommends amputation at the knee, or above, in all of the latter variety, and operation close to the point of necrosis in the former. Davies Pryce (Brain, $1893,63)$ points to the almost constant coincidence of neuritis and atheroma in diabetes. Heidenhain's review of this subject is the most thorough of any in recent years (Deut. Med. Woch., 1891, xvii. 1097, $1111,1123,1144,1163)$. He believes that diabetic gangrene is in most, if not in all, cases due to arteriosclerosis. His statistics are quite convincing. According to him, spontaneous gangrene in diabetics is pathologically identical with senile gangrene. Heidenhain also calls attention to the very frequent occurrance, even in early adult life, of urterio.sclerosis in diabetics. The cases which I have found reported are all in that period of life when this arterial lesion is to be expected. The only cases in earlier years of life are one, a girl of 19, in whom gangrene developed after an operation for cataract, and one of gangrene of the lungs in a child 8 months old (E. Wegli, Arch. für. Kinderheilkunde, B. xix). In many of the cases of diabetic gangrene on record no mention is made of the condition of the arteries. In all in which mention is made of the the state of the arteries, arteriosclerosis existed, with one exception, which was a case described by Rosenblath (Arch. für Path. Anat. Berlin, 1888, exiv, 202.210). Very numerous areas of circumscribed necrosis occurred upon the skin and mucous membranes of this patient. No vascular lesions were discernible at autopsy. Hebb (Westminster Hosp. Rep., lx, 1895, 113) describes another noteworthy case, which shows that every time gangrene occurs in diabetics, it is not due to either neuritis or arterio-sclerosis in the affected limb. Gangrene of the right arm developed with the symptoms usually caused by embolism. At the autopsy it was found to be due to an embolus consisting of a vegetation which had broken from an atheromatous ulcer in the arch of the aorta. Arteritis was general, but beginning, not advanced.

Williamson thinks that perforating ulcer of the foot in diabetes is due to neuritis. He bases his belief on clinical, not postmortem evidences. Mild neuritis is extremely common in diabetes and occasionally a severe form of lesion is demonstrable. In case two, just described above, frequently indiscribable, uneasy and uncomfortable, but not painful sensations are felt in the legs. He had no knee jerk. There may be evidences of mild neuritis. Most frequently neuritis and arterio-sclerosis occur together.

Hunt says that areas of gangrene in diabetics are mapped out by a less defined line of demarkation than in cases of senile gangrene. The literature of the subject does not corroborate this statement, nor do my own observations.

Surgeons have been disinclined to operate upon 
diabetics because of their susceptibility to infection. when opposed to commercial interests, may involve Recent experience has shown, however, that amputa- him in losses of reputation and business which may tions can be performed upon them with good success, last for a lifetime.

provided only sufficient care is taken to prevent This was the state of affairs in Texas during the infection. Heidenhain (Deut. Med. Wochen., 1891, summer and autumn of 1897. So long as yellow $\mathrm{xvii}$ ) recommends that if gangrene is confined to the fever was supposed to prevail east of the Mississippi toes the physician wait until a line of demarkation only, and that dengue was the epidemic disease in develops, and if there is no evidence of general in- Texas, peace reigned; but when the trouble came to fection, that the dead tissue be allowed to separate our own doors by the announcement of yellow fever spontaneously. If, however, the sole or dorsum of in Galveston and Houston, there came the contest the foot is involved, the leg should be amputated at over the question of diagnosis, with visits of local the knee or above it. This is a rule which my reading experts from city to city, the gradual passing of the convinces me is correct. I, however, think that am- epidemic with no record of deaths from yellow fever, putation of the toe, after a line of demarkation has and the popular conviction of a stupendous error become well established, is preferable to the tedium committed by those who believed in the presence of and pain of spontaneous amputation. The greatest that disease. The majority, both of physicians and pains should be taken to gently remove the sloughing laymen in the State are firm in the conviction that tissues, and by the free use of antiseptics to limit putrefaction.

It goes without saying that the diabetes sbould receive as much attention as the gangrene. Treatment appropriate to it should be carefully carried out.

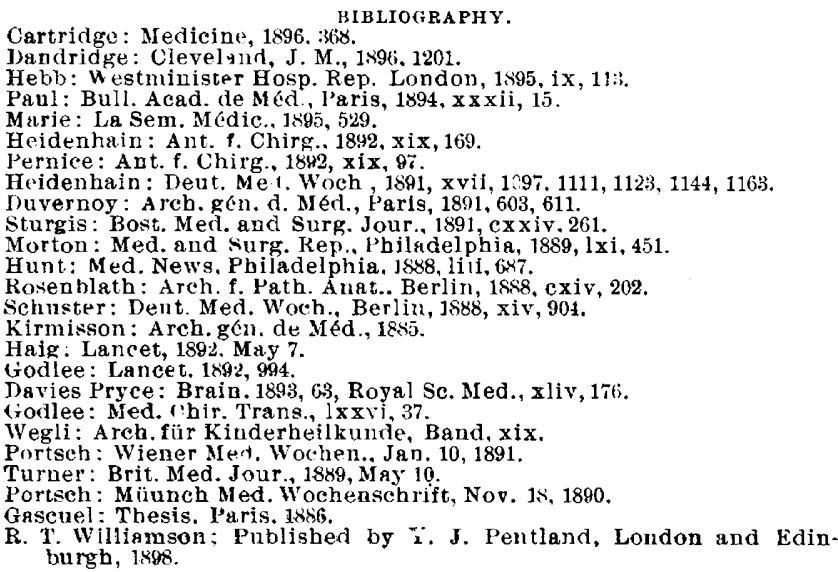

THE DIFFERENTIAL DIAGNOSIS BETWEEN DENGUE AND YELLOW FEVER. WITH SOME ACCOUNT OF THE EPIDEMIC OF 1897 IN TEXAS.

Presented to the Stetion on Practice of Medicine at the Forty-ninth Annual Meteting of the American Medical Association, held at Denver, Colo., June $7-10,1898$.

BY H. A. WEST, M.D.

GALESTON, TEXAS.

The diagnosis of disease is universally and justly regarded as the foundation stone upon which rests the entire supersitructure of practical medicine. The question concerns the health, life or death of the individual affeeted, his family and friends, the public in so far as he may be a useful and influential mem. ber of society, and the physician as affording a basis for his prognosis and treatment. But there are occasions when far more momentous interests are involved in the correct diagnosis of prevailing diseases: a complete paralysis of commerce, the wheels of industry arrested, enforced idleness with consequent poverty and suffering of thousands, enormous depreciation in property values of every kind, universal fear and panic, and the possibility of wide-spread death and desolation. To the physician himself an error in diagnosis ordinarily involves results which are comparatively inconsequential; on the other hand, there are times when such an error means public denunciation and disapprobation. A correct diagnosis, even dengue was the disease which was prevalent in Texas during the past summer; a minority believe that yellow fever also prevailed, but that owing to its mild form, indisposition to spread, exceptionally small mortality and resemblance to dengue was usually unrecognized. Confusion has arisen in the minds of many. They ask themselves, "Are the land-marks all swept away? Have the authorities led us astray? Has a new disease, anomalous dengue, made its appearance? Is there no such thing as dengue? Is the so called dengue a mild form of yellow fever? Does the latter arise de novo?"

The important issues dependent upon a knowledge and recognition of the truth upon these points render it not only pertinent but imperative upon the part of those who are familiar with the facts to study them in concert. Now that the obscuring mists due to commercialism, prejudice and passion, have for the most part passed away, we approach the subject from a scientific standpoint. It is with this end in view and in no spirit of dogmatism or self-assertion that I introduce the subject for consideration.

The following hypotheses have been assumed in relation to the recent epidemic:

1. The disease was dengue only. There was no yellow fever in Galveston, Houston, or the State of Texas in 1897.

2. There were anomalous cases of dengue, presenting all the symptoms of yellow fever, but proven not to be that disease, by the indisposition to spread from numerous foci and the low mortality rate.

3. During the progress of an intense epidemic of dengue throughout the State, in Galveston, Houston, and possibly other places, yellow fever made its appearance, and in consequence of its mild form and resemblance to the prevalent disease was generally unrecognized.

4. An imputed hypothesis that the epidemic of 1897 in Texas was yellow fever only.

5. A few cases terminating fatally, and others attended by marked jaundice and albuminuria were denominated acute infectious jaundice (Weil's disease).

In order to obtain definite information upon the subject, the following circular of inquiry was distributed to a limited extent. I regret very much that replies could not have been obtained from every infected place in the State, so as to have made the report an exhaustive one. The subjoined tabular statement, will, I trust, afford sufficient data upon which to base some definite conclusions. Following is the circular of inquiry: 